\title{
Bioelectrochemical Systems for Clean Environment
}

\section{Maallah R, Moutcine A and Chtaini A*}

Molecular Electrochemistry and Inorganic Materials Team, Sultan Moulay Slimane University, Beni Mellal Faculty of Science and Technology, Morocco

\begin{abstract}
The aim of this work is to introduce bacteria into the matrix of natural phosphate to catalyze the phenol oxidation. The results showed that the NP-bacteria-CPE exhibited excellent electro catalytic activity to phenol. The appearance of three peaks of oxidation shows that the degradation of the phenol was total.
\end{abstract}

Keywords: Modified electrodes; Cyclic voltammetry; Natural phosphate; Phenol

\section{Introduction}

Phenol is considered as a toxic product, it is one of the first compounds inscribes into the List of Priority Pollutants by the US Environmental Protection Agency (US EPA). Phenol is really a refractory hazardous pollutant in wastewater. Phenolic compounds are present in effluents from coke production, food industries, and chemical industries, such as those associated to the production of resins and pesticides, and petroleum refineries [1]. Various technologies have been studied for the recovery or destruction of phenols [2,3]. These methods are mostly based on biological treatment [4], on the phenol polymerization on anode [5-7], or on electro-oxidation on a variety of electrodes. In this work, we couple biological and electrochemical treatment. The bioelectrochemical system developed is based on a carbon paste electrode modified by a natural phosphate matrix, in which we have introduced a well-defined quantity of bacteria.

\section{Experimental}

\section{Apparatus and software}

All electrochemical measurements were invested by using a voltalab potentiostat (model PGSTAT 100, Eco Chemie BV., Utrecht, The Netherlands) driven by the general purpose electrochemical systems data processing software (Master 4 software) run under windows 2007. The three electrode system consisted of a modified carbon paste electrode as the working electrode a saturated calomel electrode (SCE) serving as reference electrode, and platinum as an auxiliary electrode.

\section{Electrodes}

Modified electrodes were prepared by mixing a carbon powder and the desired weight of natural phosphate doped with an amount of bacteria. The body of the working electrode for voltammetric experiments was a PTFE cylinder that was tightly packed with carbon paste. The geometric area of this electrode was $0.1256 \mathrm{~cm}^{2}$. Electrical contact was made at the back by means of a bare carbon.

\section{Procedure}

The prepared electrode is first characterized in electrolytic medium. In a second stage is tested for the electrooxidation of phenol, added in the measurement cell. The mixture solution was kept for $20 \mathrm{~s}$ at open circuit and deoxygenated by bubbling pure nitrogen gas prior to each electrochemical measurement. The cyclic voltammetry was recorded in the range from $-1.5 \mathrm{~V}$ to $1,5 \mathrm{~V}$. Optimum conditions were established by measuring the peak currents in dependence on all parameters. All experiments were carried out under ambient temperature [5].
The bacteria used in this study are Staphylococcus aureus. The bacteria were cultivated in medium LB (Luria Burtani) solid. After sterilization in the autoclave of the culture medium, the bacteria were sown there and then incubation was done with $37^{\circ} \mathrm{C}$ during $24 \mathrm{~h} \mathrm{[7].}$

Provisions were taken for deoxygenation by splashing the solution with nitrogen gas during approximately $5 \mathrm{~min}$. In order to obtain reliable and reproducible results, a new electrolyte was prepared for each handling.

\section{Results and Discussion}

\section{Natural phosphate characteristics}

The morphological characterization of the natural phosphate (NP) used in this work, was invested by Scanning Electron Microscopy (MEB) (Figure 1). We find that the NP matrix is formed by compact particles fractions between 100 and $400 \mathrm{~mm}$ that is rich in phosphate and as can been seen that compact NP appearance was evident. The treated NP has following chemical composition:

$\mathrm{CaO}(54,12 \%), \mathrm{P}_{2} \mathrm{O}_{5}(34,24 \%), \mathrm{F}^{-}(3,37 \%), \mathrm{SiO}_{2}(2,42 \%), \mathrm{SO}_{3}$ $(2,21 \%), \mathrm{CO}_{2}(1,13 \%), \mathrm{Na}_{2} \mathrm{O}(0,92 \%), \mathrm{MgO}(0,68 \%), \mathrm{Fe}_{2} \mathrm{O}_{3}(0,36 \%)$, $\mathrm{K}_{2} \mathrm{O}(0,04 \%)$ and several metals in the range of ppm.

We can notice that the surface of the NP presents an important porosity and a considerable roughness. The crystal structure of NP matrix is similar to that of fluoroapatite $\left(\mathrm{Ca}_{10}\left(\mathrm{PO}_{4}\right) 6 \mathrm{~F}_{2}\right)$, as shown by X-ray diffraction (Figure 2) and infrared emission spectroscopy (Figure 3). The network of fluoroapatite is very tolerant of substitution is vacant sites, such as $\mathrm{Ca}$ can be replaced by $\mathrm{Sr}, \mathrm{Sb}, \mathrm{Co}$ and $\mathrm{Na}, \mathrm{PO}_{4}$ by $\mathrm{AsO}_{4}, \mathrm{VO}_{4}$ and $\mathrm{SO}_{4}$ and $\mathrm{F}^{-}$can be replaced by $\mathrm{OH}^{-}$and $\mathrm{Cl}$. The $\mathrm{NP}$ has the characteristics of a good catalyst; in spite of its specific surface is relatively low $1 \mathrm{~m}^{2} \cdot \mathrm{g}^{-1}$ (Figures $1-3$ ).

\section{Electrochemical characterization of prepared electrode}

The cyclic voltammograms (CV's) recorded, respectively, at NP modified carbon paste electrode (NP-CPE) (curve 1) and at NP doped with bacteria modified paste electrode (NP-bacteria-CPE) (curve 2), in

*Corresponding author: Chtaini A, Molecular Electrochemistry and Inorganic Materials Team, Sultan Moulay Slimane University, Beni Mellal Faculty of Science and Technology, Morocco, Tel: 212661118521; E-mail: a.chtaini@usms.ma

Received November 28, 2016; Accepted December 01, 2016; Published December 11, 2016

Citation: Maallah R, Moutcine A, Chtaini A (2016) Bioelectrochemical Systems for Clean Environment. J Biosens Bioelectron 7: 231. doi: 10.4172/2155-6210.1000231

Copyright: @ 2016 Maallah R, et al. This is an open-access article distributed under the terms of the Creative Commons Attribution License, which permits unrestricted use, distribution, and reproduction in any medium, provided the original author and source are credited. 

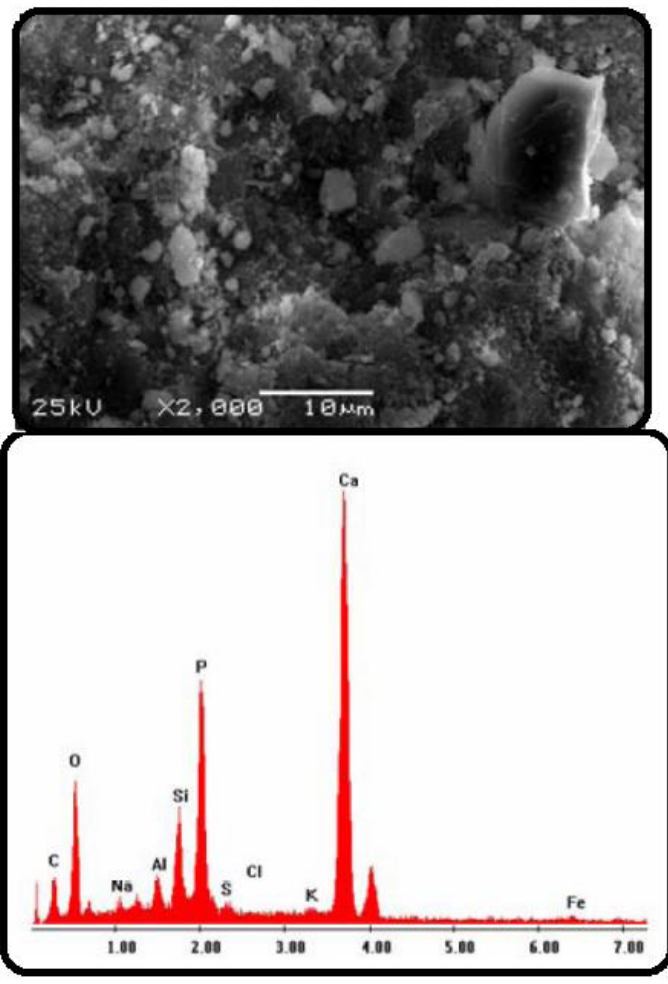

Figure 1: Scanning Electron Micrograph of Natural Phosphate.
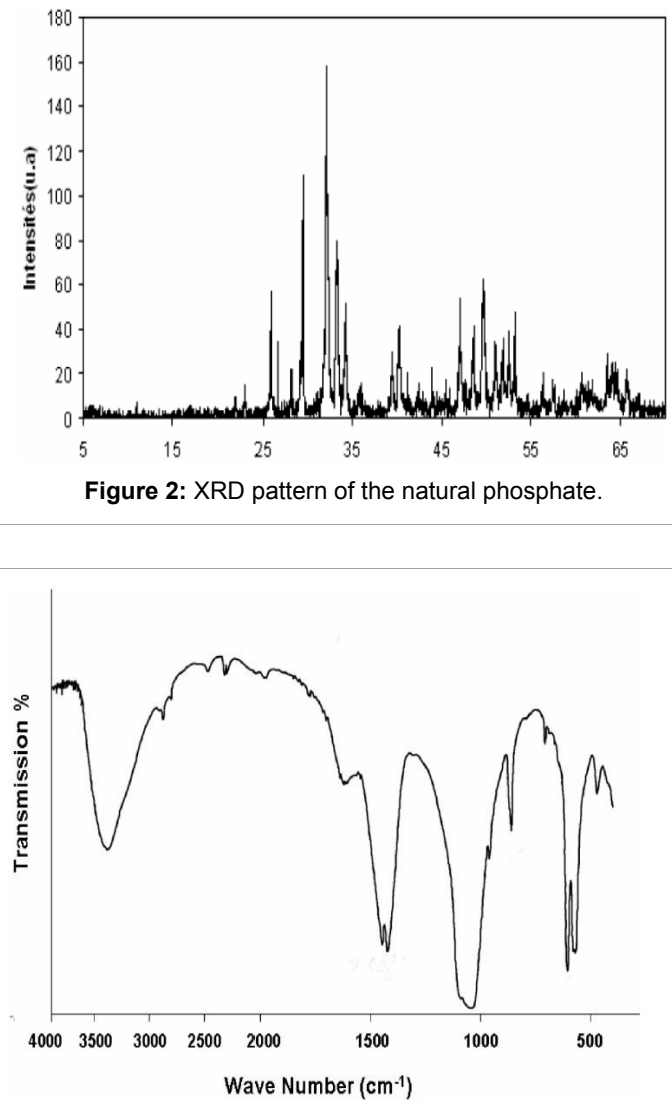

Figure 3: IR spectra of natural phosphate.

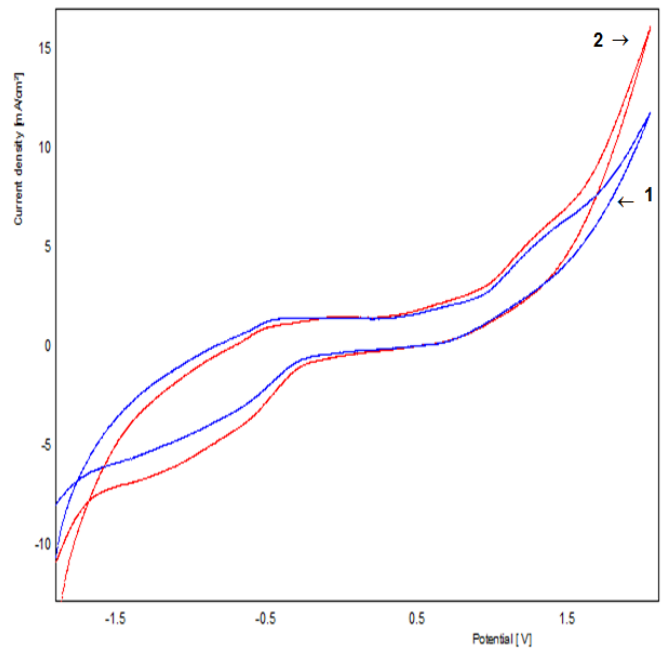

Figure 4: CV's recorded at, 1- NP-CPE and 2- NP-bacteria-CPE, in 0.1M $\mathrm{Na}_{2} \mathrm{SO}_{4}$ solution

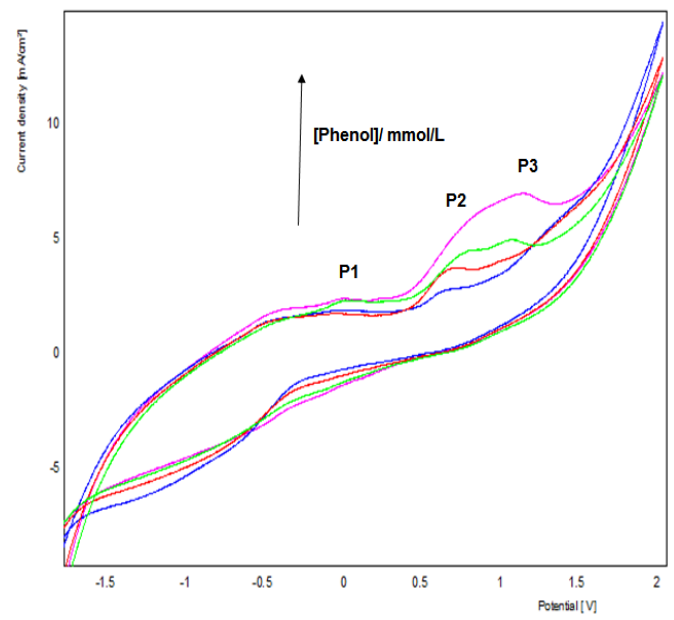

Figure 5: CV's recorded at NP-bacteria-CPE, in electrolytic medium containing various concentrations of phenol, at $100 \mathrm{mV} . \mathrm{s}^{-1}$.

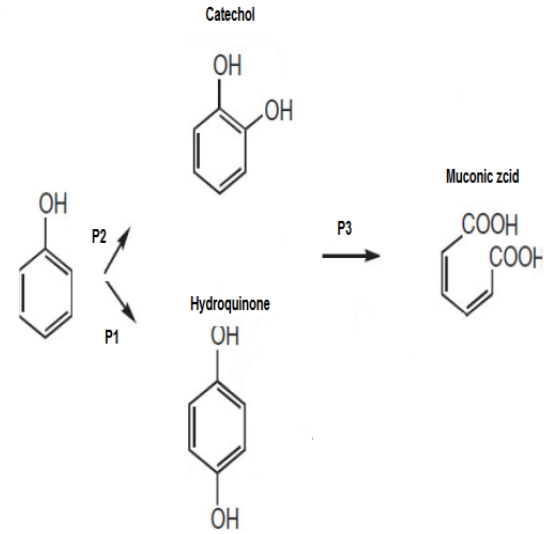

Scheme 1: Mechanism of electrochemical oxidation of phenol at NP-bacteriaCPE. 
supporting electrolyte $\left(0.1 \mathrm{M} \mathrm{Na}_{2} \mathrm{SO}_{4}\right)$, are shown in Figure 4 . We can notice that in both cases CV's keep the same speed, with a light increase of electric currents densities for the NP-bacteria-CP electrode [3].

Electrooxidation of phenol was studied at NP-bacteria-CPE, by cyclic voltammetry (CV) and by square wave voltammetry (SWV). Figure 5 shows the CV's unregistered when phenol was added to electrolytic medium. The CV's exhibited three defined anodic peaks P1, $\mathrm{P} 2$ and $\mathrm{P} 3$, respectively at 0,1 and $1.4 \mathrm{~V}$. The presence of only anodic peaks, suggests that the electrochemical oxidation of phenol is totally irreversible, and we propose the following scheme, in agreement with the previous works (Figures 4 and 5 and Scheme 1).

The influence of scan rate on the oxidation peak potentials (Ep) and peak current (Ip) of phenol, were studied by CV (Figure 6). The current density, of phenol oxidation peak, increase considerably with concentration. The Figure 7 shows the linear relationship between the scan rates and the current density of anodic peak (P2), suggesting that the electron transfers of phenol at NP-bacteria-CPE is adsorption controlled reaction (Figures 6 and 7) [6].

The evolution of the peak of the phenol oxidation (P2) with according the concentration was also followed by SWV. The current

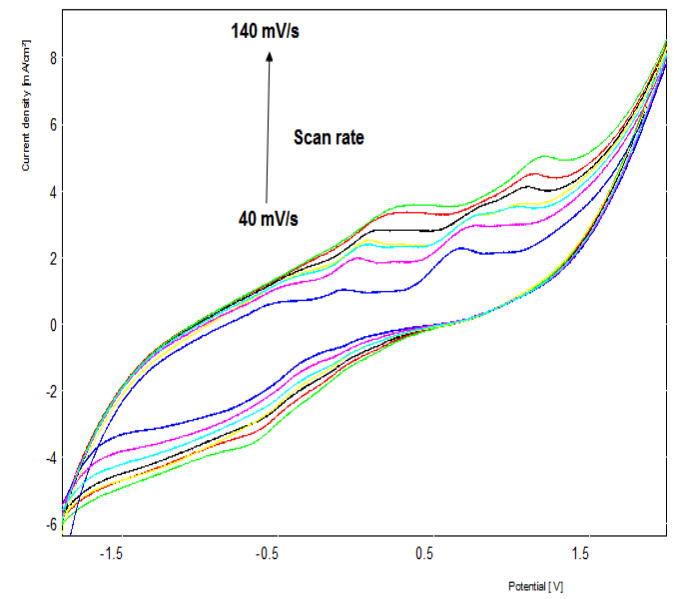

Figure 6: CV's recorded at NP-bacteria-CPE, in electrolytic medium containing phenol, at various scan rates.

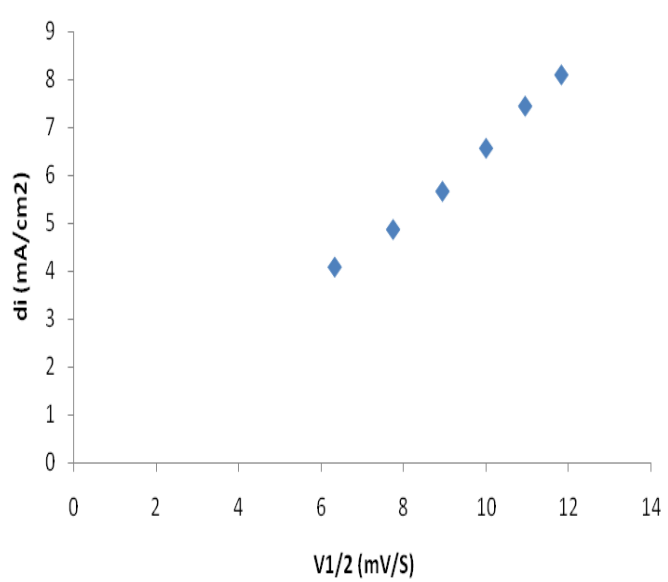

Figure 7: Plot of peaks area versus scan rate.

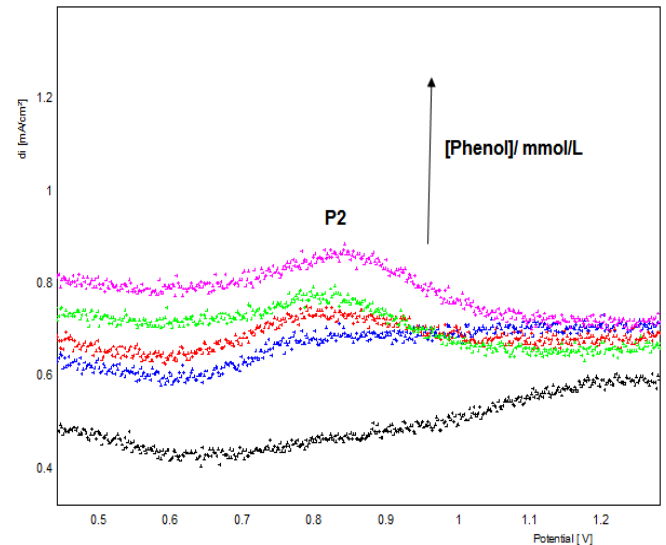

Figure 8: SWV recorded at NP-bacteria-CPE, in electrolytic medium containing phenol.
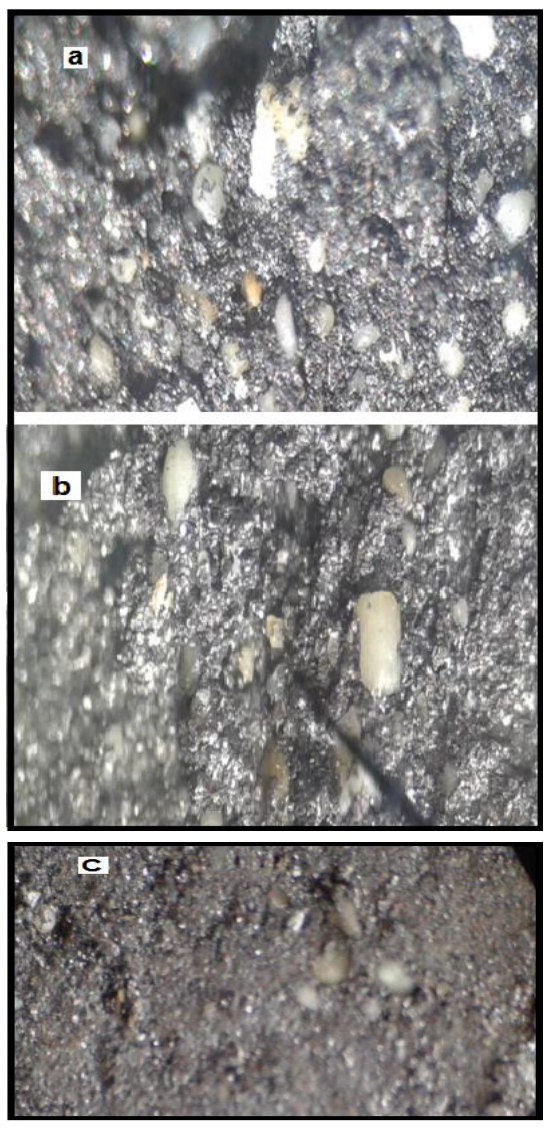

Figure 9: Optical microscopy of NP-bacteria-CPE.

density increases with the concentration of the phenol, what means that the prepared electrode possesses a significant number of active site (Figure 8).

The morphological study of the surface of the prepared electrode was invested by metallographic microscopy (Figure 9). The prepared electrodes were imaged by optical microscopy. After phenol oxidation, the morphology of the prepared electrode surface changes aspect, it shows agglomerates scattered on the entire surface. 
Citation: Maallah R, Moutcine A, Chtaini A (2016) Bioelectrochemical Systems for Clean Environment. J Biosens Bioelectron 7: 231. doi: 10.4172/21556210.1000231

\section{References}

1. Saravanan $P$, Pakshirajan $K$, Saha $P(2009)$ Treatment of phenolics containing synthetic wastewater in an internal loop airlift bioreactor (ILALR) using indigenous mixed strain of Pseudomonas sp. under continuous mode of operation. Bioresource Technol 100: 4111-4116. .

2. Li P, Takahashi M, Chiba K (2007) Free-radical generation from collapsing microbubbles in the absence of a dynamic stimulus. Chemosphere 75: 13431347.

3. Tahar NB, Savall A (2009) Electrochemical removal of phenol in alkaline solution. Contribution of the anodic polymerization on different electrode materials. Electrochim Acta 54: 4809-4816.
4. Xavier LN, Ortega E, Ferreira JZ, Bernardes AM, Pérez-Herranz V (2011) An electrochemical Study of Phenol Oxidation in Acidic Medium. Int J Electrochem Sci 6: 622-636.

5. Mengoli G, Musiani MM (1986) Protective coatings on iron by anodic oxidation of phenols in oxalic acid medium. Electrochim Acta 31: 201-210.

6. Kawaguchi H (1992) Illustrated Handbook of Physical-Chemical Properties. Chemosphere 24: 1707.

7. Devlin HR, Harris IJ (1984) Mechanism of the oxidation of aqueous phenol with dissolved oxygen. Industrial and Engineering Chemistry Fundamentals 23(1984)387-392. 